\title{
Importancia de los cuidados de la favi para la prolongación de su vida útil
}

\author{
Miguel Echeguren Aiz, Itxaso Bengoa Urreta, Rosario Calvo Marín, $M^{a}$ Angeles Nogales Rodríguez, Ma José \\ Fuentes Medina, Ascensión Garay Pérez
}

Unidad de Hemodiálisis. S. Nefrología. Hospital Universitario de Álava - Txagorritxu. Osakidetza. VitoriaGasteiz. Álava

\section{Objetivo:}

Analizar la influencia del correcto cuidado de la FAVI con su vida útil.

\section{Descripción del caso:}

Paciente, mujer, de 70 años de edad, en programa de hemodiálisis desde 06/09/1999.

- El 25/2/2008 se realiza FAVI radiocefálica izquierda a la paciente.

- El 12/5/2009 realizan fistulografía tras empeoramiento de los flujos arteriales confirmándose estenosis de 8 $\mathrm{cm}$. en zona arterial. Colocan prótesis autoexpandible corrigiéndose el flujo arterial y mejorando el Kt/V.

- El 7/9/2009 realizan Eco Doppler por sospecha de rechazo del stent no objetivándose datos concluyentes de dicha situación.

- El 16/10/2009 realizamos nueva fistulografía por evidencia de decúbito con exteriorización del stent siendo claramente visible un tramo de $1,5 \mathrm{~cm}$ con pérdida de la continuidad de la piel. A pesar de la intensa proliferación intimal, la FAVI es normofuncionante.

- Durante los 2 años siguientes la FAVI continúa normofuncionante, con ausencia de infecciones y sin mayor proliferación del stent.
- El 24/5/2012 se trombosa la FAVI por razones ajenas al problema expuesto. Cuidados de la FAVI:

- Durante el periodo desde el 25/2/08 hasta el 12/8/09 se aplican los cuidados básicos de la FAVI siguiendo el protocolo de la unidad.

- El 12/8/09 se objetiva infección con abundante exudado purulento, recogiéndose cultivo y comenzando curas con Bactroban pomada. Tras evaluar resultados del cultivo se pauta protocolo de Vancomicina intravenosa (IV) (dosis inicial de $1 \mathrm{gr}$ y 9 dosis de $500 \mathrm{mg}$ en días de hemodiálisis) resolviéndose la infección tras completar el tratamiento.

- Tras evidenciarse la exteriorización del stent, se realizan curas con suero fisiológico y Betadine más apósito en cada sesión de hemodiálisis, además de los propios autocuidados de la FAVI. De esta manera no se vuelven a presentar signos de infección ni alteraciones en el normofuncionamiento de la FAVI.

\section{Conclusiones:}

A pesar de importantes complicaciones (exteriorización de stent e infección) en la FAVI, unos correctos cuidados de la misma permiten la prolongación de su vida útil. 